\title{
Thermoregulation of exercising men in the morning rise and evening fall phases of internal temperature
}

\author{
Masafumi Torii ${ }^{*} \mathrm{PhD}$, Hideaki Nakayama ${ }^{\dagger}$ MD PhD and Takashi Sasaki ${ }^{\ddagger}$ MD PhD \\ *Bioregulation and Physical Fitness Laboratory, Faculty of Engineering, Kyushu Institute of Technology, \\ Kitakyushu 804, Japan; ${ }^{+}$Department of Hygiene, Faculty of Medicine, Tottori University, Yonago 683, Japan and \\ ‡Environmental Physiology Laboratory, Ginkyo Junior College, Kumamoto 860, Japan
}

\begin{abstract}
The purpose of this study was to compare the thermoregulatory responses during exercise in the morning rise $(0900 \mathrm{~h})$ and evening fall phases $(2000 \mathrm{~h})$ in circadian variation of body temperature. Five healthy volunteers performed bicycle exercises at $30 \%$ and $60 \%$ of maximal aerobic power $\left(\dot{V}_{\mathrm{O}_{2}}\right)$ at $26^{\circ} \mathrm{C}$ with a relative humidity of $50 \%$. Whole-body sweat rate $(\mathrm{SR})$, rectal $\left(\bar{T}_{\text {re }}\right)$, mean skin $\left(\bar{T}_{\text {sk }}\right)$ and mean body $\left(\bar{T}_{\mathrm{b}}\right)$ temperature, pulmonary ventilation $\left(\dot{V}_{E}\right)$, oxygen uptake $\left(\dot{V}_{\mathrm{O}_{2}}\right)$, and carbon dioxide output $\left(\dot{V} \mathrm{CO}_{2}\right)$ and heart rate (HR) were measured during the experimental period. SR during exercise at $30 \% \quad \dot{V O}_{2 \max }$ was significantly higher at $2000 \mathrm{~h}$ than at $0900 \mathrm{~h}$. However, the circadian variation of SR during exercise was not observed at $60 \% \dot{V}_{O_{2} \max }$. At the two experimental times, there were also no significant differences in $\dot{V}_{\mathrm{O}_{2}}, \dot{V} \mathrm{CO}_{2}, \dot{V}_{\mathrm{E}}$ and $\bar{T}_{\text {sk }}$ in both workloads. In HR, $\bar{T}_{\mathrm{b}}$ and $T_{\text {re }}$ circadian effects were demonstrated as well as in workload levels. As $\bar{T}_{b}$ was plotted against SR during exercise, positive correlations were observed. The data showed that there was a parallel shift in the SR to $\bar{T}_{b}$ relationship during exercise in the morning and evening. This rightward shift indicated that there was an increased $\bar{T}_{b}$ threshold for the onset of sweating in the evening. Resting $\bar{T}_{b}$ at $2000 \mathrm{~h}$ was significantly higher when compared with $\bar{T}_{b}$ at $0900 \mathrm{~h}$. The present results suggest that the circadian influence on the thermoregulatory response to exercise may be evident only at low workloads.
\end{abstract}

Keywords: temperature regulation, sweat rate, work intensity, circadian rhythm

The circadian rhythm in human body temperature appears to be regulated, rather than just the consequence of passive imbalances in the rate of heat production and heat loss ${ }^{1-4}$. Several of the following thermal physiological parameters to exercise and heat stress were shown to exhibit circadian rhythmicity: sweating $5-8$, skin blood flow ${ }^{5,8,9}$, body temperature ${ }^{5-8}$ and heart rate ${ }^{10}$. Aschoff and Heise ${ }^{11}$ estimated that in a resting man the circadian variations of heat loss were responsible for about $75 \%$ of the range of oscillation in internal temperatures, while the variation in heat production contributed only $25 \%$.

Address for correspondence: Dr M. Torii, Bioregulation and Physical Fitness Laboratory, Faculty of Engineering, Kyushu Institute of Technology, Sensui 1 - 1, Tobata, Kitakyushu 804, Japan
Hirdebrandt $\mathrm{t}^{12}$ reported that the circadian control of human body temperature was the result of the following thermoregulatory adjustments: warmingup in the morning and cooling-down in the afternoon. However, identification of the factors that cause the circadian fluctuation has been more controversial.

It was previously reported by Niwa et al. ${ }^{6}$ that there were a circadian rhythm of thermoregulatory response. Under the condition of an environmental temperature at $13^{\circ} \mathrm{C}$ with a relative humidity of $60 \%$, the sweating response during bicycle exercise at workload of $450 \mathrm{kpm} \mathrm{min}^{-1}(75 \mathrm{~W})$ was at its maximum at $1800 \mathrm{~h}$ and its minimum at $0600 \mathrm{~h}$, but heat production during exercise was identical at various periods during the day. However, no report was given on thermoregulatory response at different work intensities. The aim of the present study, therefore, was to investigate temperature regulatory responses at two different work intensities in the morning rise and evening fall phases in the human body temperature, and to discuss the circadian control mechanism contributed by the work factor.

\section{Materials and methods}

\section{Subjects}

The subjects selected were five healthy male college students, mean(s.e.m.) age 21.6(0.7) years, 171.8(2.7) $\mathrm{cm}$ in height, $68.8(2.5) \mathrm{kg}$ in weight, $1.83(0.04) \mathrm{m}^{2}$ of body surface area $\left(=\right.$ height $^{0.178} \times$ weight $^{0.427} \times 71.84$ of Takahira's equation ${ }^{13}$, and with maximal aerobic power $\left(\dot{V}_{\mathrm{O}_{2} \max }\right)$ of $3.07(0.16) 1 \mathrm{~min}^{-1}$ (mean(s.e.m.)). During the first visit to the laboratory, each subject was oriented to the basic equipment and procedures used in the experiment. Practice time was provided for riding the bicycle ergometer and performing the mouth piece for oxygen uptake $\left(\dot{V}_{2}\right)$ measurement. Before the main experiments, each participant's $\dot{V}_{\mathrm{O}_{2}}$ max was determined by an incremental work rate protocol on a Monark bicycle ergometer using the Douglas bag technique ${ }^{14}$. The pedalling rate was kept constant at $50 \mathrm{rpm}$ and timed with a metronome. After $2 \mathrm{~min}$ of pedalling with a constant load $720-780 \mathrm{kpm} \mathrm{min}^{-1}(120-130 \mathrm{~W})$, the work intensity was increased by $150 \mathrm{kpm} \mathrm{min}^{-1}(30 \mathrm{~W})$ every minute up to exhaustion. Before the main experiment, we 
also measured circadian variation of oral temperature in our subjects (Figure 1), and confirmed morning rise and evening fall in oral temperature.

\section{Experimental protocol}

The subjects arrived at the laboratory at least $1 \mathrm{~h}$ before the experiments, and sat quietly until the designated time. They undressed except for their

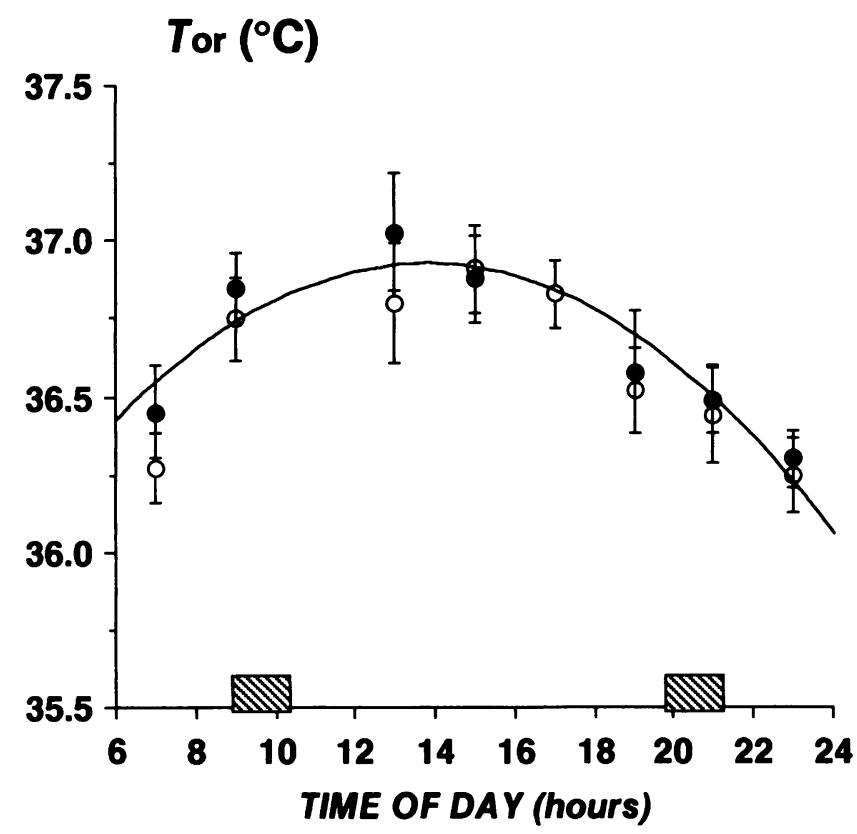

Figure 1. Circadian variations of mean oral temperature $\left(T_{\text {or }}\right)$ of resting subjects $(n=5)$. Shaded areas represent the time period of the experiment. Resting oral temperature shows a diurnal increase and a nocturnal decrease, followed by an early morning increase. In the figure a quadratic line indicates its equation, $y=35.3+0.229 \mathrm{x}$ $-8.3160 \mathrm{x}^{2}, r=0.933$. $O=1$ st measurement, $O=2$ nd measurement. The periods of the present experiments are represented by two shaded areas underwear. The experiments were done at two different times of the day, and each experiment was on a different day. The experiments were at $0900 \mathrm{~h}$ and $2000 \mathrm{~h}$, with all studies starting within $30 \mathrm{~min}$ of the target time. The four experiments were carried out from October to early November, with the order randomized. The work intensities were both $30 \%$ and $60 \%$ of $\dot{V}_{\mathrm{O}_{2} \text { max }}$ in each subject. After sitting on a chair for $30 \mathrm{~min}$ at the condition of thermoneutrality, they conducted a bicycle exercise for $40 \mathrm{~min}$ in a mean(s.d.) ambient temperature $\left(T_{\mathrm{a}}\right)$ of $26^{\circ} \mathrm{C}\left(0.7^{\circ} \mathrm{C}\right)$ with a mean(s.d.) relative humidity (rh) of $50 \%(7.3 \%)$. An experimental work test was performed on 20 separate days, two at each of following times: $0900 \mathrm{~h}$ and $2000 \mathrm{~h}$. No muscular work was performed for $24 \mathrm{~h}$ before any test. In the morning on an experimental day, the subjects conducted the cycle exercise without taking breakfast, and in the case of the experiments in the evening on another day kept no kaloric intake six to eight $h$ after taking lunch (usual foods) at $1300-1400 \mathrm{~h}$.

\section{Measurements}

Sweating rate (SR) was measured continuously from whole body weight loss, using a bed scale (Model $33 \mathrm{~B}$, sensitivity, $\pm 1.0 \mathrm{~g}$ J.A. Potter Co., Southington, Conneticut, USA) technique, as described previously ${ }^{15,16}$. The best curve shown in Figure 2 was drawn through the weight record for each experiment and rate of whole-body weight loss was then calibrated prior to each experiment. Respiratory evaporative weight loss was estimated by Mitchell et al. ${ }^{17}$.

The temperatures of four skin surface locations and rectum $\left(T_{\text {re }}\right)$ at a depth of $15 \mathrm{~cm}$ from the anus were recorded every $5 \mathrm{~min}$ by a copper-constantan thermocouple recording system (AM-300, Ohkura Electric Co. Ltd, Japan) with an accuracy of $\pm 0.05^{\circ} \mathrm{C}$ throughout the experimental period. Mean skin temperature $\left(\bar{T}_{\mathrm{sk}}\right)$ and mean body temperature $\left(\bar{T}_{\mathrm{b}}\right)$
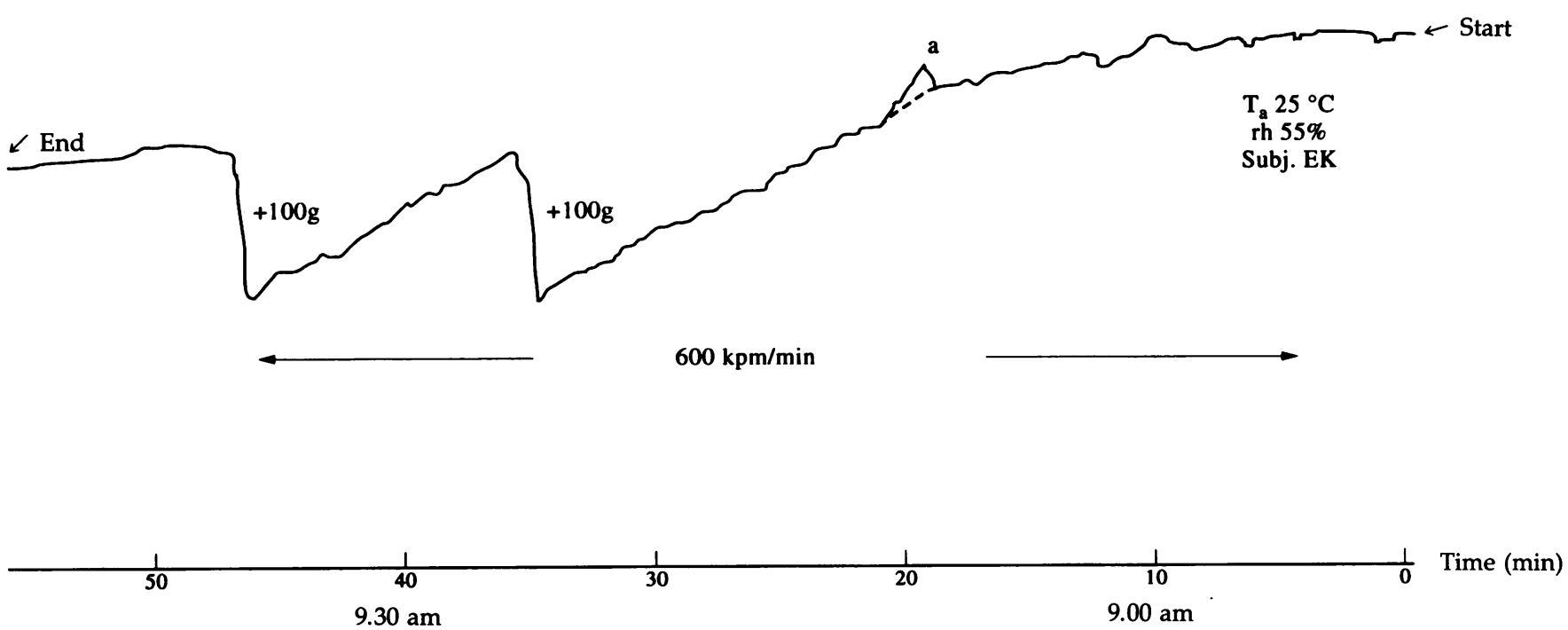

Figure 2. A recording example of the whole body weight loss measured by a bed scale. After $15 \mathrm{~min}$ of exercise (at $100 \mathrm{~W} \cdot=$. $600 \mathrm{kpm} \mathrm{min}^{-1}$ ) the weight loss increased markedly. $100 \mathrm{~g}$ scales were indicated in the centre of a chart. The curve of weight losses was modified at the point $a$, because a thermocouple sensor dropped 
were calculated from Ramanathan's ${ }^{18}$ and StolwijkHardy's ${ }^{19}$ equations, respectively.

Heart rate (HR) was recorded by electrocardiography with a telemeter system (Model 270 and 1418, Sanei Sottki, Japan). $\mathrm{VO}_{2}$ was determined by the Douglas bag technique at rest and during exercise, 5-, 10-, 20-, 30-, 40-min after the beginning of exercise and during recovery. The gas samples were immediately analysed for oxygen (F-3, Beckman Fullerman, California, USA) and carbon dioxide (MCD-L, Horiba Seisakusho, Japan). Expired gas volume was measured with a gas meter (WT-10, Shinagawa Seisakusho Co, Japan).

\section{Statistical analysis}

Values represent the mean \pm s.e.m., and statistically significant differences of mean values were assessed by a paired $t$ test and one-way ANOVA. We also evaluated time of day and work intensity to thermal response during exercise by means of two-way ANOVA. The significance of the regression line was also evaluated by covariance analysis. A probability level of 0.05 or less was accepted as a significant difference.

\section{Results}

No individual differences were found among the subjects in all the data related to sweating responses at rest and during exercise $(P>0.05$, one-way ANOVA).

Figure 3 shows the time courses of $\dot{\mathrm{O}}_{2}$ during exercise at two different work intensities at $0900 \mathrm{~h}$ and $2000 \mathrm{~h}$. While all subjects sat quietly on a bicycle ergometer, their mean(s.e.m.) $\dot{V}_{\mathrm{O}_{2}}$ was not significantly different between $0900 \mathrm{~h}\left(309(19.2) \mathrm{ml} \mathrm{min}^{-1}\right.$, $n=10)$ and $2000 \mathrm{~h}\left(306(12.2) \mathrm{ml} \mathrm{min}^{-1}, n=10\right)$. At the end of the two test periods at $30 \% \dot{V}_{\mathrm{O}_{2} \max }$ and $60 \%$ $\dot{V} \mathrm{O}_{2}$ max $\quad \dot{V} \mathrm{O}_{2}$ measured during exercise averaged $1.000(0.06)$ and $1.611(0.06) 1 \mathrm{~min}^{-1}$ and $1.041(0.05)$ and $1.635(0.03) 1 \mathrm{~min}^{-1}(P>0.05)$, respectively. At all phases of the two test periods, $\mathrm{V}_{2}$ during exercise at $60 \% \quad \dot{V O}_{2} \max$ was significantly higher than $30 \%$ $\dot{V}_{\mathrm{O}_{2 \max }}$ (two-way ANOVA). There were also no significant differences in carbon dioxide output and pulmonary ventilation in both workloads and at the conducted experimental time.

The time courses of HR during exercise at two different work intensities at $0900 \mathrm{~h}$ and $2000 \mathrm{~h}$ are represented in Figure 4. HR, at $25-40 \mathrm{~min}$ after the onset of exercise at $60 \% \quad \dot{V}_{\mathrm{O}_{2} \max }$, was significantly higher at $2000 \mathrm{~h}$ than $0900 \mathrm{~h}$. However, there was not a significant difference in the $\mathrm{HR}$ between $0900 \mathrm{~h}$ and $2000 \mathrm{~h}$ during exercise at $30 \% \dot{V}_{\mathrm{O}_{\text {max }}}$. At all phases of the two test periods, HR during exercise at $60 \%$ $\dot{V} \mathrm{O}_{2 \max }$ was significantly higher than $30 \% \quad \dot{V} \mathrm{O}_{2 \max }$ (two-way ANOVA).

The time courses of SR during exercise at two different work intensities at $0900 \mathrm{~h}$ and $2000 \mathrm{~h}$ are shown in Figure 5. SR during exercise at $30 \% \dot{V}_{\mathrm{O}_{2} \max }$ (left), was significantly higher at $2000 \mathrm{~h}$ than $0900 \mathrm{~h}$. At $60 \% \dot{V}_{\mathrm{O}_{2} \max }$ exercise (right), SR was not significantly different, except for $20 \mathrm{~min}$ after the onset of exercise at $0900 \mathrm{~h}$ in comparison with $2000 \mathrm{~h}$. At all phases of the two test periods, SR during exercise at $60 \% \quad \dot{V}_{2} \max$ was significantly higher than $30 \%$ $\dot{V} \mathrm{O}_{2 \max }$ (two-way ANOVA). As shown in Table 1, at $30 \% \mathrm{VO}_{2 \max }$ exercise TSR and $\mathrm{SR}_{\max }$ were significantly higher at $2000 \mathrm{~h}$ than at $0900 \mathrm{~h}$. In contrast, other parameters showed no significant differences between $0900 \mathrm{~h}$ and $2000 \mathrm{~h}$ in exercise at $60 \% \dot{V}_{\mathrm{O}_{2} \max }$. Furthermore, at $60 \% \dot{V}_{\mathrm{O}_{2} \max }$ exercise, the time of reaching $S R_{\max }$ was faster at $2000 \mathrm{~h}$ than at $0900 \mathrm{~h}$ $(P<0.01)$, but there was not significant difference of the time of reaching $S R_{\max }$ between $0900 \mathrm{~h}$ and $2000 \mathrm{~h}$

\section{V̇O2 $\left(1 \cdot \mathrm{min}^{-1}\right)$}

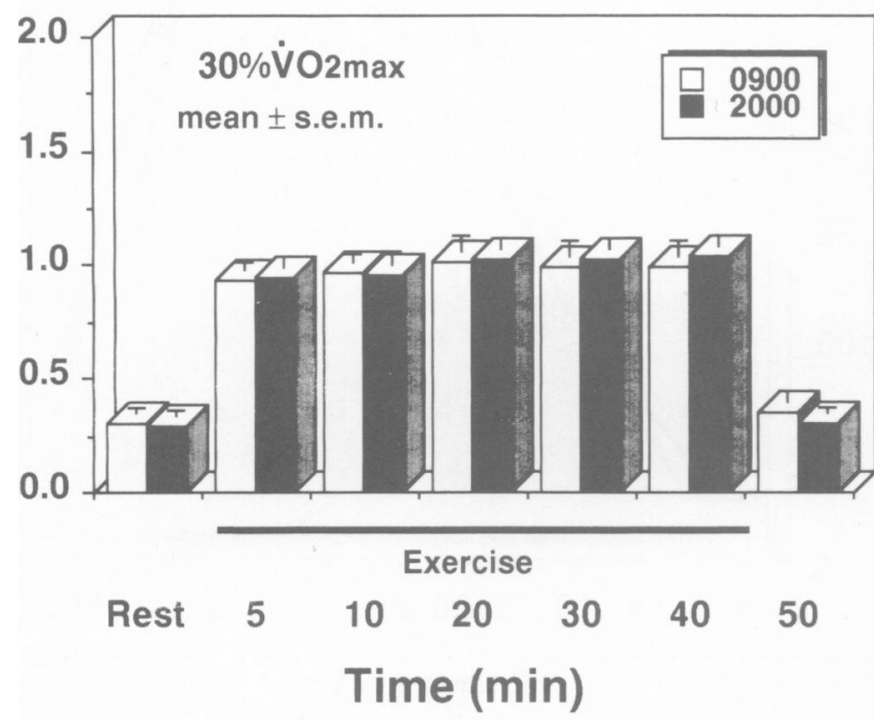

\section{VंO2 (I. $\left.\mathrm{min}^{-1}\right)$}

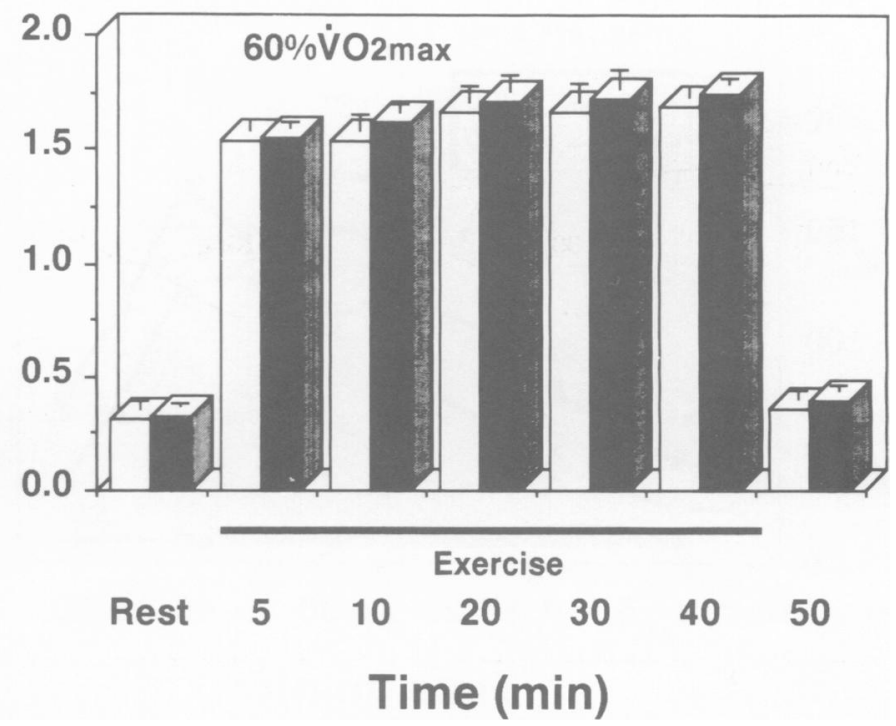

Figure 3. Time courses of $\dot{V}_{\mathrm{O}_{2}}$ in exercising men at two different workloads, about $30 \%$ [left] and $60 \%$ [right] of $\dot{V}_{2}$ max in the later morning $[\square]$ and evening [ $\square]$. Horizontal bars indicate an exercise period. Data represent mean(s.e.m.) for five subjects 
Circadian variation of thermoregulation during exercise: $M$. Torii et al.

in exercise at $30 \% \quad \dot{V} \mathrm{O}_{2 \max }$. At rest insensible perspiration also was significantly higher at $2000 \mathrm{~h}$ and $0900 \mathrm{~h}$ (Table 1).

Figure 6 illustrates the time courses of $T_{\text {re }}$ (top), $\overline{\mathrm{T}}_{s k}$ (middle) and $\bar{T}_{\mathrm{b}}$ (bottom) during exercise at two

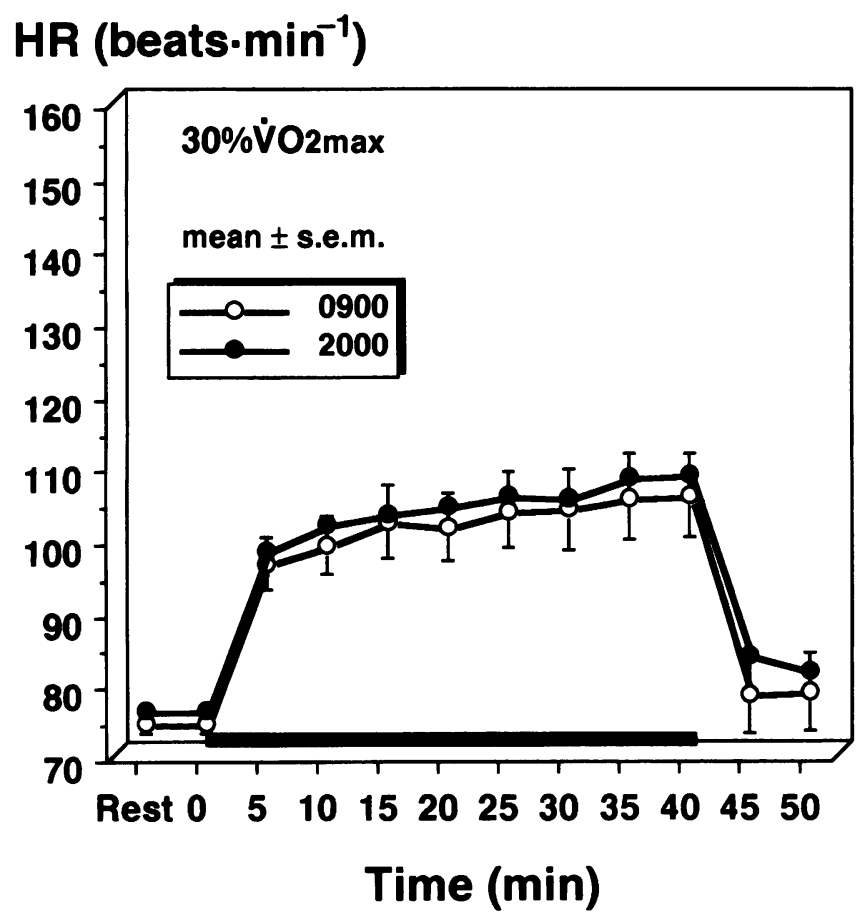

different work intensities at $0900 \mathrm{~h}$ and $2000 \mathrm{~h}$. Mean(s.d.) $T_{\text {re }}$ had an initial value of $37.49(0.03)^{\circ} \mathrm{C}(n$ $=5$ ), and did not change during the $40 \mathrm{~min}$ of work at $2000 \mathrm{~h}$ (Figure 6, top and left). At $0900 \mathrm{~h}, \mathrm{~T}_{\text {re }}$ increased slightly reaching values of $37.17(0.12)^{\circ} \mathrm{C}(n=5)$ at

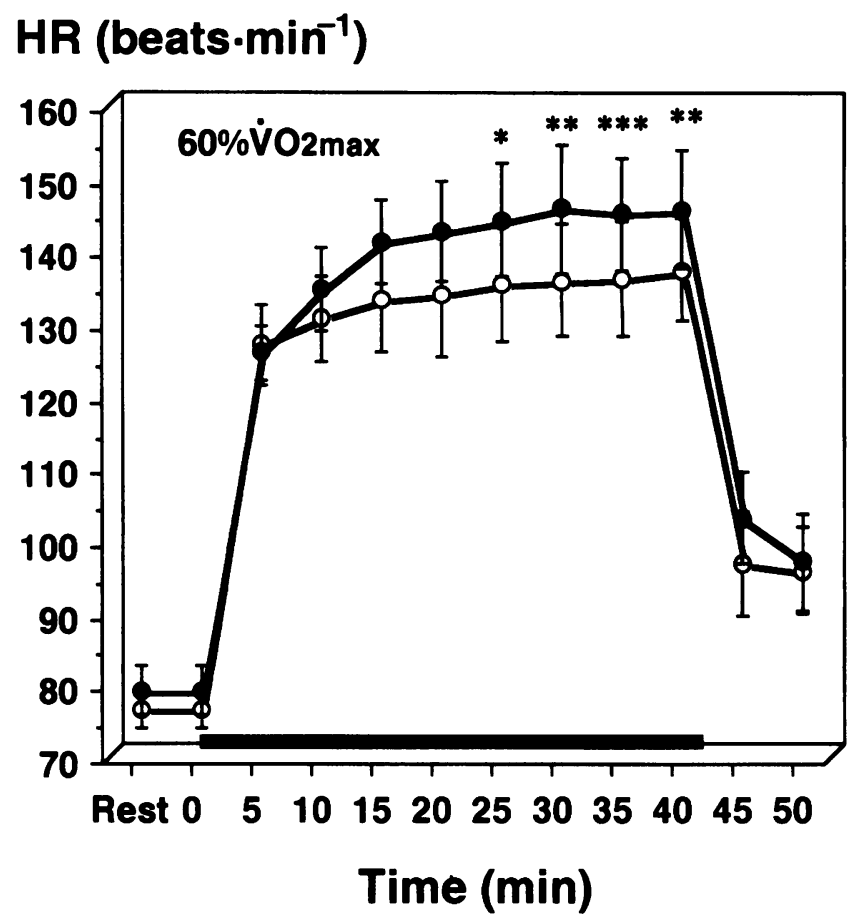

Figure 4. Time courses of HR in exercising men at two different workloads, about $30 \%$ [left] and $60 \%$ [right] of $\dot{V}_{\mathrm{O}_{2}}$ max in the later morning $[\mathrm{O}]$ and evening [O]. Horizontal bars indicate an exercise period. Data represent mean(s.e.m.) for five subjects. Significantly different (paired $t$ test), $0.900 \mathrm{~h}$ vs. $2000 \mathrm{~h},{ }^{*} P<0.05,{ }^{* *} P<0.01,{ }^{* * *} P<0.001$
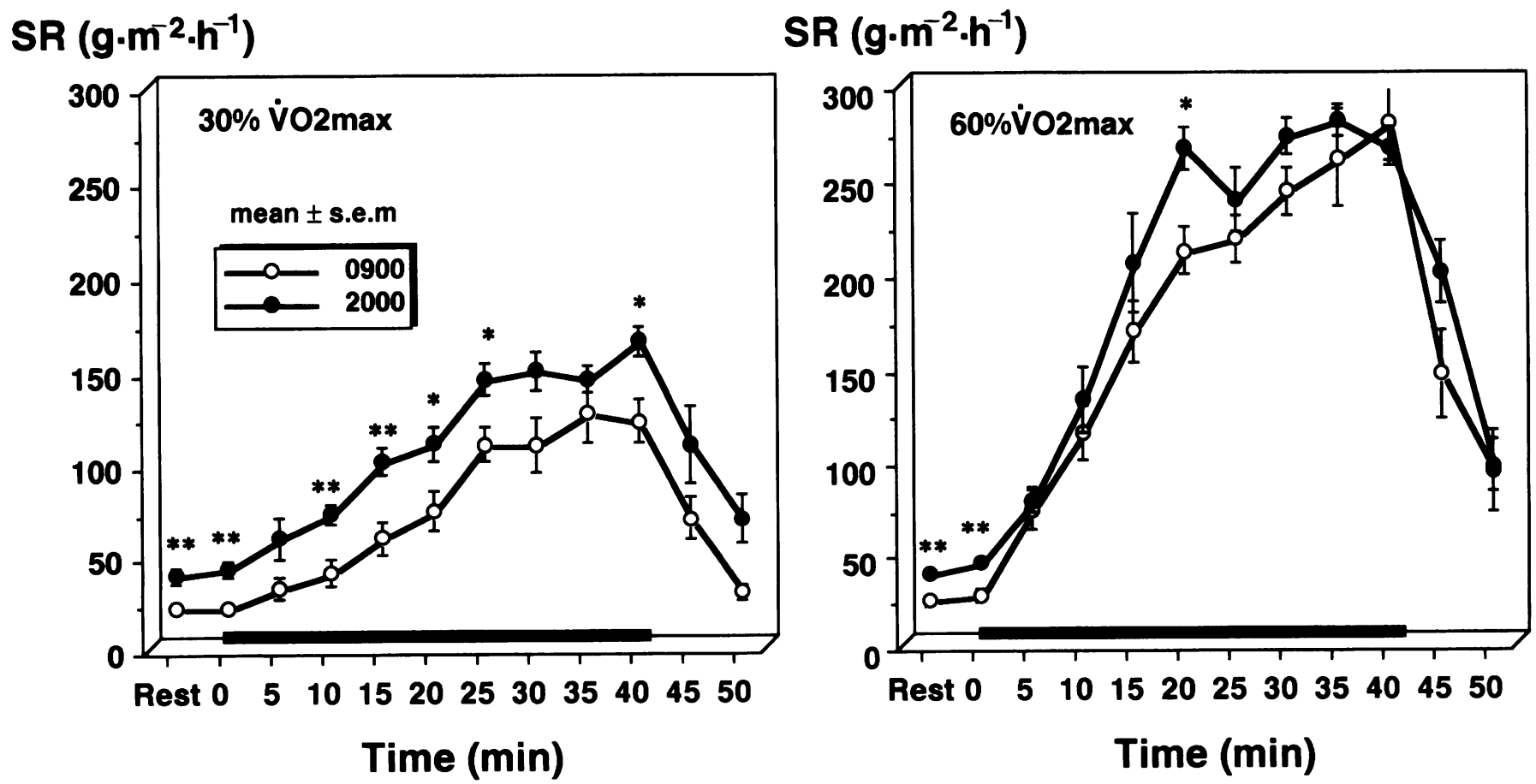

Figure 5. Time courses of SR in exercising men at two different workloads, about $30 \%$ [left] and $60 \%$ [right] of $\dot{V}_{\mathrm{O}_{2}}$ max in the later morning $[\mathrm{O}]$ and evening [O]. Horizontal bars indicate an exercise period. Data represnt mean(s.e.m.) for five subjects. Significantly different (paired $t$ test) $0900 \mathrm{~h}$ vs. $2000 \mathrm{~h},{ }^{*} P<0.05,{ }^{* *} P<0.01$ 
Table 1. Circadian variation of thermoregulatory responses in exercising men at two different work intensities

\begin{tabular}{|c|c|c|c|c|}
\hline & \multicolumn{2}{|c|}{$30 \% \dot{V}_{O_{2} \max }$} & \multicolumn{2}{|c|}{$60 \% \dot{V}_{O_{2 \max }}$} \\
\hline & $0900 h$ & $2000 \mathrm{~h}$ & $0900 \mathrm{~h}$ & $2000 \mathrm{~h}$ \\
\hline $\begin{array}{l}\operatorname{TSR}\left(\mathrm{g} \mathrm{m}^{-2} \mathrm{~h}^{-1}\right) \\
\operatorname{SR} R_{\max }\left(\mathrm{g} \mathrm{m}^{-2} \mathrm{~h}^{-1}\right) \\
\operatorname{TR~SR}_{\max }(\min ) \\
\Delta T_{\mathrm{re}}\left({ }^{\circ} \mathrm{C}\right) \\
\Delta \bar{T}_{\mathrm{sk}}\left({ }^{\circ} \mathrm{C}\right) \\
\Delta \bar{T}_{\mathrm{b}}\left({ }^{\circ} \mathrm{C}\right)\end{array}$ & $\begin{array}{c}83.0(8.0) \\
138.4(10.0) \\
37(1.2) \\
0.27(0.07)^{*} \\
1.20(0.11) \\
0.45(0.05)\end{array}$ & $\begin{array}{c}117.3(2.8)^{*} \\
167.4(6.1)^{*} \\
33(3.0) \\
0.11(0.04) \\
1.42(0.36) \\
0.37(0.09)\end{array}$ & $\begin{array}{c}194.4(8.7)^{\dagger} \\
283.4(17.1)^{\dagger} \\
38(1.2) \\
0.70(0.10)^{\dagger} \\
1.21(0.16) \\
0.79(0.07)^{\dagger}\end{array}$ & $\begin{array}{c}216.2(11.0)^{\dagger} \\
287.4(5.2)^{\dagger} \\
29(2.4)^{* *} \\
0.61(0.02)^{\dagger} \\
0.85(0.02) \\
0.61(0.07)^{+}\end{array}$ \\
\hline
\end{tabular}

Data represent mean(s.e.m.) for five subjects; TSR, total sweat rate for 40 min of exercise; $S_{R_{\max }}$ maximum rate of sweating during exercise; TR SR max $_{\text {, time of reaching SR }}$ max after the onset of exercise; $\Delta T_{\text {re }}, \Delta \bar{T}_{\text {sk }}$ and $\Delta \bar{T}_{\mathrm{b}}$, changes from pre-exercise value in $T_{\text {re, }}, \bar{T}_{\mathrm{sk}}$ and $\bar{T}_{\mathrm{b}}$, respectively; Significant difference (paired $t$ test), $0900 \mathrm{~h}$ vs $2000 \mathrm{~h},{ }^{*} P<0.05,{ }^{* *} P<0.01 ; 30 \% \dot{V O}_{2 \max }$ vs $60 \% \dot{V}_{\mathrm{O}_{2 \max },}{ }^{+} P<0.01$

Tre $\left({ }^{\circ} \mathrm{C}\right)$

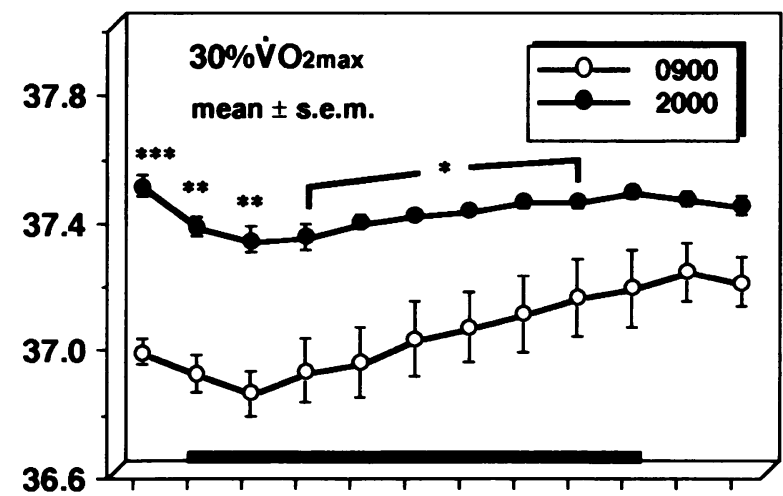

$\overline{\mathbf{T}}_{\text {sk }}\left({ }^{\circ} \mathrm{C}\right)$

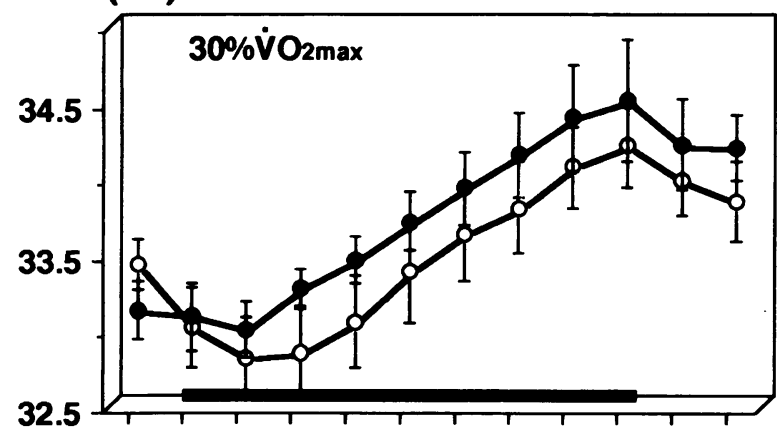

$\overline{\mathrm{T}}\left({ }^{\circ} \mathrm{C}\right)$

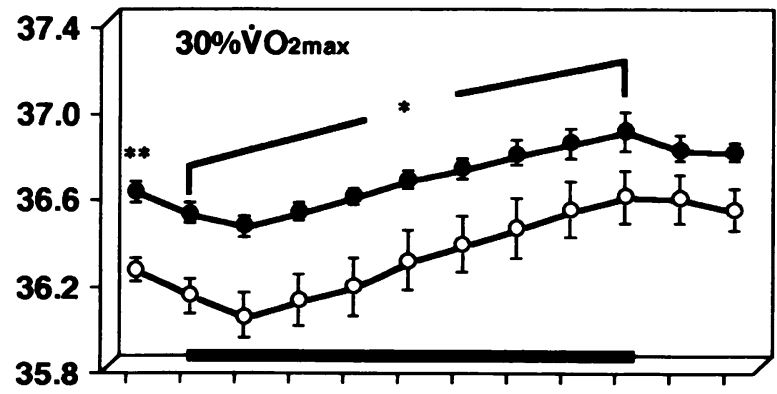

Rest 05101520253035404550

Time (min)
Tre $\left({ }^{\circ} \mathrm{C}\right)$

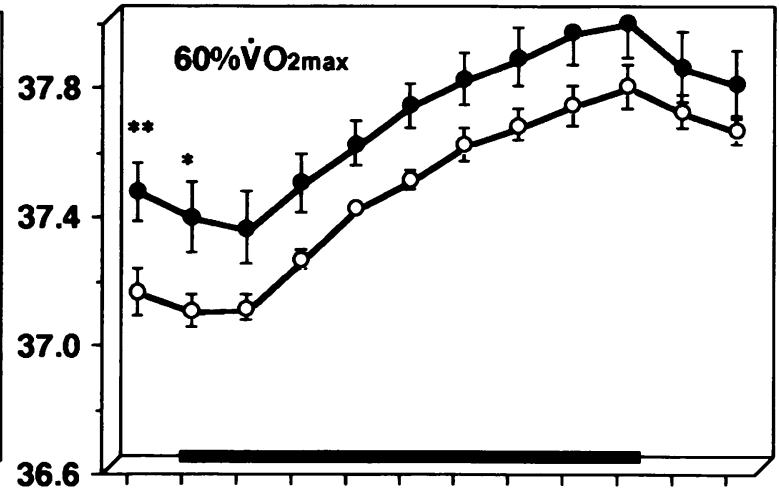

$\overline{\mathrm{T}}_{\text {sk }}\left({ }^{\circ} \mathrm{C}\right)$

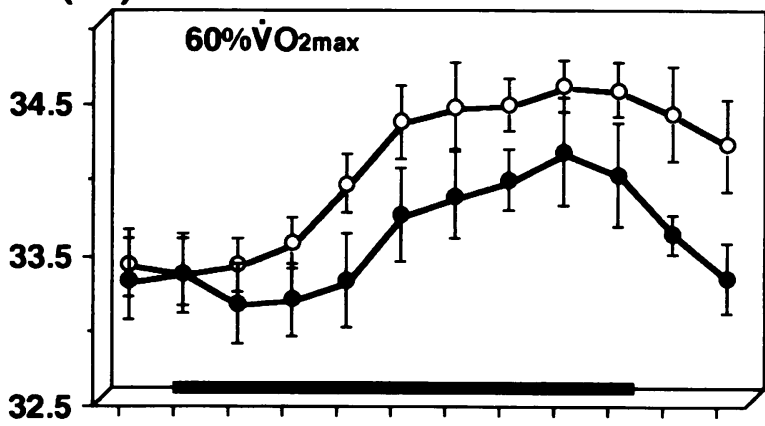

$\overline{\mathrm{T}}_{\mathrm{b}}\left({ }^{\circ} \mathrm{C}\right)$

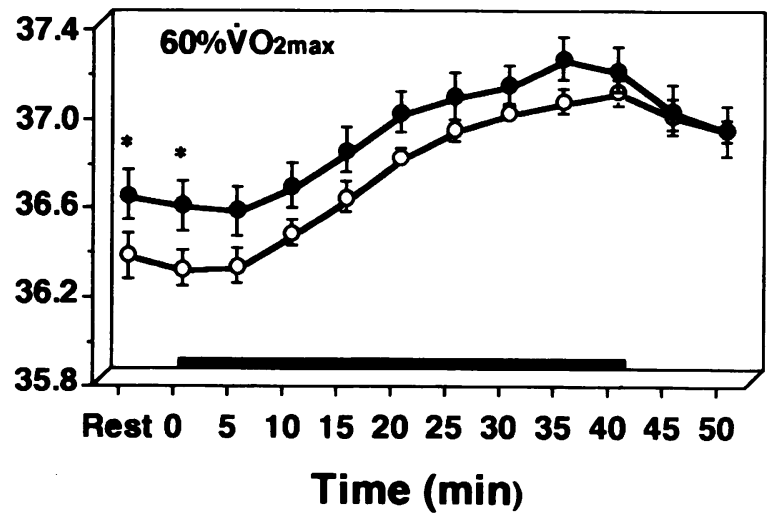

Figure 6. Time courses of $T_{\text {re, }}, \bar{T}_{\mathrm{b}}$ and $\bar{T}_{\text {sk }}$ in exercising men at two different workloads, about $30 \%$ [left] and $60 \%$ [right] of $\mathrm{V}_{2}$ max in the later morning [O] and evening [O]. Horizontal bars indicate an exercise period. Data represent mean(s.e.m.) for five subjects. Significantly different (paired $t$ test), $0900 \mathrm{~h}$ vs. $2000 \mathrm{~h},{ }^{*} P<0.05,{ }^{* *} P<0.01,{ }^{* * *} P<0.001$ 
$40 \mathrm{~min}$. There was no significant difference between $T_{\text {re }}$ at $0900 \mathrm{~h}$ and at $2000 \mathrm{~h}$, except for $40 \mathrm{~min}$ after the onset of exercise at $30 \% \mathrm{VO}_{2 \max }$ exercise. There was a significant difference in the rate of increase in $T_{\mathrm{re}}$ between $0900 \mathrm{~h}$ and $2000 \mathrm{~h}$ during exercise at $30 \% \dot{V}_{2}$ max. In both periods, $\bar{T}_{\mathrm{b}}$ levels peaked during exercise at $60 \% \dot{V}_{\mathrm{O}_{2} \text { max }}$. None of these changes were significant, suggesting no significant changes in $\bar{T}_{\mathrm{b}}$ during the exercise in both periods. However, at $30 \%$ $\dot{V}_{\mathrm{O}_{2} \max }$ exercise $\bar{T}_{\mathrm{b}}$ was significantly higher at $0900 \mathrm{~h}$ than at $2000 \mathrm{~h}$. No significant difference in $\bar{T}_{\text {sk }}$ was found between $2000 \mathrm{~h}$ and $0900 \mathrm{~h}$ in both workloads (Figure 6, bottom). After a transient fall, $\bar{T}_{\text {sk }}$ slightly increased during exercise at the two different workloads of the two test periods. For sitting on a bicycle ergometer (at rest) $T_{\mathrm{re}}$ and $\bar{T}_{\mathrm{b}}$ also were significantly higher at $2000 \mathrm{~h}$ and $0900 \mathrm{~h}$. There was no significant difference in $\bar{T}_{\text {sk }}$ between $0900 \mathrm{~h}$ and $2000 \mathrm{~h}$ in the resting condition on a bicycle ergometer (Table 1).

As $\vec{T}_{\mathrm{b}}$ was plotted against SR during exercise, positive correlations were observed (Figure 7). In all
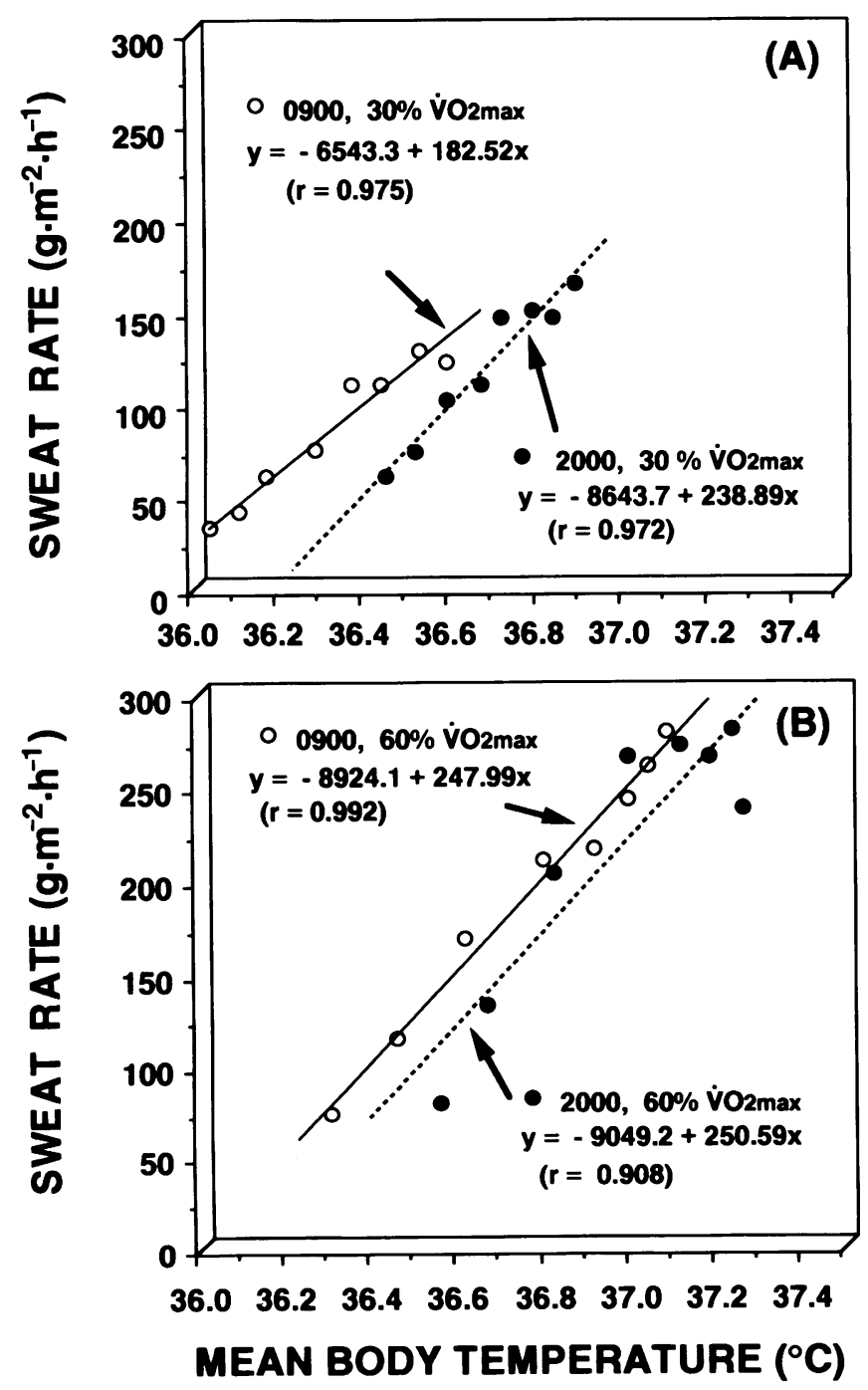

Figure 7. Relationship between $S R$ and $\bar{T}_{\mathrm{b}}$ in exercising men at two different workloads $30 \%[\mathrm{~A}]$ and $60 \%[\mathrm{~B}]$ of $\dot{V}_{\mathrm{O}_{2} \text { max }}$ in the later morning [O] and evening [O]. SR and $\bar{T}_{\mathrm{b}}$ were mean values during exercise for five subjects subject data concerning SR vs $T_{\mathrm{re}} \bar{T}_{\mathrm{sk}}$ and $\bar{T}_{\mathrm{b}}$ relations (or the relation of SR to $T_{\text {re, }} T_{\text {sk }}$ or $\bar{T}_{\mathrm{b}}$ ), the best correlation coefficient $(r=0.8201)$ was observed in the SR vs $\bar{T}_{\mathrm{b}}$ relation. The regression equations and correlation coefficients are presented in Figure 7. Analysis of covariance revealed significant differences of the slope and intercept between the regression lines (SR vs $\bar{T}_{\mathrm{b}}$ relationship) at $0900 \mathrm{~h}$ and $2000 \mathrm{~h}$ to exercise at $30 \% \dot{V}_{2} \max (P<0.05$, respectively). At $60 \% \dot{V}_{\mathrm{O}_{2} \max }$ exercise the intercept shifted to a higher temperature $(P<0.05)$.

\section{Discussion}

The circadian rhythm of different physiological and biochemical variations has been well established. A number of investigators studied the daily courses of $\mathrm{SR}^{5,6,8}$, peripheral blood flow ${ }^{5,8,9}, \dot{\mathrm{O}}_{2 \max }{ }^{20}$ and $\mathrm{HR}^{10}$ in muscular working humans. A nocturnal lowering human core temperature has been correlated with a lowering to the core temperature threshold for cutaneous vasodilation and sweating during exercise ${ }^{5}$ and rest to a heat exposure ${ }^{21}$. Timbal et al. ${ }^{7}$ investigated at $0200 \mathrm{~h}, 1000 \mathrm{~h}$ and $1800 \mathrm{~h}$ during a heat exposure of $90 \mathrm{~min}$, sweat rate, body temperature and heat storage of the body of human subjects. According to their calculating and measuring data, the relationship between the change of heat storage of the body $(\Delta S)$ in the morning and that during the night is expressed in the following equation: $\Delta S_{\text {night }}$ $=0.69 S_{\text {morning }}-6.24$. In the present study, SR during exercise at the lower work intensity was significantly higher in the evening than in the morning. In this case, we were in agreement with the previous reports $^{6,8}$. However, the circadian variation of SR during exercise was not observed at the heavy work intensity. In the previous studies, there was no comparison made of the effects of work intensity on the circadian control to temperature regulation. In the present study $T_{\mathrm{re}}$ and $\bar{T}_{\mathrm{b}}$ at rest (values before exercise) were significantly higher at $0900 \mathrm{~h}$ than $2000 \mathrm{~h}$. From our data, it suggests that heat dissipating activity in the central control system is activated more in the evening than in the later morning.

At the heavy workload, the HR of exercising men in the evening was significantly higher than that in the later morning. $\mathrm{VO}_{2}$ however, increased in proportion to workloads, not to time of day (two-way ANOVA). No measurements were made of other physiological parameters in cardiorespiratory function. The present study suggests that, for cardiospiratory function and skin circulation during exercise, the regulatory system circulation may be modified by the work factors. Cohen and Muehl ${ }^{16}$ reported that there was circadian variation of $\mathrm{HR}$ during submaximal exercise. In resting $\mathrm{HR}$, they also noted 50 beats $\min ^{-1}$ at $0400 \mathrm{~h}$ and 70 beats $\min ^{-1}$ at $1800 \mathrm{~h}$ during the time of day. We, however, did not observe HR in a resting condition, and did not compare directly with their subject laying (supine) on a bed, because our subjects were seated on a bicycle ergometer. Further studies are required to measure other physiological parameters such as cardiac output, stroke volume and skin blood flow.

A typical rightward shift in $\bar{T}_{\mathrm{b}}$ threshold for $\mathrm{SR}$ was 
shown in the data (Figure 7). SR was graphed as a function of $\bar{T}_{\mathrm{b}}$ during two different exercises in the morning and evening. The data showed that there was a parallel shift (rightward) in the SR to $\bar{T}_{b}$ relationship during exercise in the later morning and evening. This rightward shift indicated that there was an increased $\bar{T}_{b}$ threshold for the onset of sweating in the evening. The increased threshold temperatures for sweating and vasodilation, observed by Stephenson et al. ${ }^{8}$, were affected by the normal circadian rhythm in resting_internal temperature. In our experiment, resting $\bar{T}_{\mathrm{b}}$ in the evening was significantly higher $(P<0.001)$ in comparison with that in the later morning. This result supported the concept that the regulation of sweating is related to a critical level of $\bar{T}_{b}$ or heat storage of the body ${ }^{22}$. In another study $^{23}$, the regulation of sweating was analysed in terms of the interaction between central and peripheral inputs to the thermoregulatory system. Inputs from the skin thermosensors stimulated by the rate of change in skin temperature, have been shown to play a major role in the regulation of sweating in exercising subjects ${ }^{24}$.

Although core temperature is the primary thermoregulatory drive in the control of skin sweating, skin temperature can also affect $\mathrm{SR}^{24}$. In the present study, however, there were no significant differences in skin temperature in the exercising men at two different work intensities in the later morning and the evening. These data suggest that skin temperature shifted the minimum levels to maximum levels in the early morning, or the maximal levels to the minimum levels in the afternoon, if we accept Hildebrandt's hypothesis ${ }^{12}$ on circadian control in human thermoregulation; that is, circadian regulatory mechanisms change to warming-up after $0300 \mathrm{~h}$ and the regulatory function change to cooling-down after $1500 \mathrm{~h}$. Examining the effect of a step change in environmental temperature upon the skin temperature and blood flow of a seated human, Sasaki and Carlson ${ }^{25}$ observed that the circadian change of core temperature was paralleled by variations in both skin temperatures and peripheral blood flows. They have reported cycles in the heat dissipating responses which are not readily explained by simultaneous changes in core temperature. On the other hand, the rise in core temperature of an exercising man was proportional to work intensities and largely independent of ambient temperatures between $5-30^{\circ} \mathrm{C}$. This rise in core temperature was not due to a failure in body temperature regulation, but was attributed to the setting of the body thermostat at a higher level ${ }^{26,27}$. At the same work intensity, our data differ in the rate of increase of core temperature presented by $T_{\text {re }}$ due to exercise between the later morning and evening (Table 1). Moreover, evaporative cooling indexes as $T S R, R_{\max }$ and the time to reach $\mathrm{SR}_{\max }$ did differ markedly by means of work intensity (Figure 5 and Table 1); that is, TSR and $\mathrm{SR}_{\max }$ during exercise at the heavy workload did not observe the circadian variation.

Furthermore, our data indicate that the two major independent experimental variables in evaluating the effect of exercise on temperature regulation are the condition of the internal environment such as the biological clock' 28 and the workload. Figures 5 and 6 show how these two variables cause changes in regulatory sweating, core temperature and skin temperature. In the cooling-down period, heat dissipation activity was stimulated compared to the warming-up period at the lower workload. However, effector responses dissipating heat at the heavy workload are not distinguished in both phases.

It has been reported that in an exercising human the thresholds for sweating moved toward a lower core temperature early in the morning $(0400 \mathrm{~h})^{5}$. On the other hand, in the present study a tendency was observed in humans for the changes in core temperature during thermal transient caused by exercise to be larger at the later morning phase that at the evening phase. The rise in core temperature in a man during heat and cold exposure was reported to be higher at early morning $(0200 \mathrm{~h})$ than later morning $(1000 \mathrm{~h})$ and evening $(0600 \mathrm{~h})^{7}$. These findings may reflect the fact that the thermosensitivity of an exercising man is reduced during the night. As illustrated in Figure 7, the slopes of the temperature characteristic lines might also be reduced as indicated by temperature sensitivity during the light phase in addition to the parallel shifts mentioned above. This could cause a further downward shift of set-point temperature from day to evening.

Recently, the significance of exercise prescription for a healthy lifestyle has been recognized ${ }^{29}$ but there is little practical knowledge about the physiologicalthermoregulating functions in humans, especially as affected by internal conditions ${ }^{28}$. Many works ${ }^{30-32}$ have reported that the risk factors for coronary heart disease decrease with an increase in aerobic exercise and sports (or muscular activity). Thus, an exercising man is affected by the time of day, and prescribers of exercise programmes must pay attention to factors such as exercise intensity. These findings are applicable to practical-exercise activity; that is, our data may be important in planning the practice of and in evaluating the effectiveness of a physical exercise programme.

In conclusion, the results of this study indicate that the circadian control of thermoregulatory response to exercise may be modulated by the workloads in the later morning and evening. It is suggested that the rise in human body temperature normally observed during exercise at the light workload in the later morning is due partly to the proportional nature of the circadian control mechanism and partly to the lower level in sweating which locally inhibits the heat dissipating responses due to evaporating sweat. These findings seem to have important implications for further research; for example, disappearance or lowering of the circadian variation in sweating response to exercise at the higher work intensity. The circadian variation of thermal regulation during exercise may be modulated by this factor.

\section{Acknowledgements}

The authors would like to express their gratitude to their colleagues Dr M. Yamasaki (Department of Health and Physical Education, Integrated Arts and Science, Hiroshima University) and MSc T. Miyabayashi (Laboratory of Work Physiology, Kumamoto 
Junior College) and their contributions to the experimental work presented here. We also thank Mr J. Russell (MA), Assistant Professor in the Kyushu Institute of Technology, for checking the English. This work was partly presented in the 1st International Conference of Human-Environment System, Tokyo, 1991.

\section{References}

1 Aschoff J, Pohl H. Rhythmic variations in energy metabolism. Federation Proc 1970; 29: 1541-52.

2 Sasaki T. Body temperature and its circadianity. Jiritsushinkei 1984; 21: 177-83. (in Japanese with English abstract).

3 Sasaki T. Circadian rhythm in body temperature. In: Itoh S, Ogata K, Yoshimura H, eds. Advances in Climatic Physiology. Tokyo, Japan: Igaku Shoin, 1972; 319-33.

4 Smith RE. Circadian variations in human thermoregulatory responses. I Appl Physiol 1969; 26: 554-60.

5 Wenger CB, Roberts MF, Stolwijk JAJ, Nadel ER. Nocturnal lowering of thresholds for sweating and vasodilation. J Appl Physiol 1976; 41: 15-19.

6 Niwa K, Nakayama T, Ohnuki Y, Midorikawa T. Circadian variation of thermoregulatory responses during exercise in male. Jpn J Phys Fitness Sports Med 1982; 3: 258-65 (in Japanese with English abstract).

7 Timbal J, Colin J, Boutelier C. Circadian variations in the sweating mechanism. J Appl Physiol 1975: 39: 226-30.

8 Stephenson LA, Wenger CB, O'Donovan BH, Nadel ER. Circadian rhythm in sweating and cutaneous blood flow. Am J Physiol 1984: 246: R321-4.

9 Kaneko M, Zechman FW, Smith RE. Circadian variation in human peripheral blood flow levels and exercise responses. J Appl Physiol 1968; 25: 109-14.

10 Cohen CJ, Muehl GE. Human circadian rhythms in resting and exercise pulse rate. Ergonomics 1977; 20: 475-9.

11 Aschoff J, Heise A. Thermal conductance in man: its dependence on time of day and on ambient temperature. In: Itoh $\mathrm{S}$, Ogata $\mathrm{K}$, Yoshimura $\mathrm{H}$ eds. Advances in Climatic Physiology. Tokyo, Japan: Igaku Shoin, 1972; 334-48.

12 Hildebrandt $G$. Circadian variations of thermoregulatory response in man. In: Scheving LE et al. eds. Chronobiology. Tokyo, Japan: Igaku Shoin, 1974; 234-40.

13 Takahira $\mathrm{H}$. A study of metabolic rate in the Japanese; surface area in the Japanese and its estimation equation. Eiyo Kenkyusho Hokoku 1925; 1: 61-95 (in Japanese).

14 Miyamura M, Honda Y. Oxygen intake and cardiac output during maximal treadmill and bicycle exercise. J Appl Physiol 1972; 32: 185-8.

15 Torii M, Yamasaki M, Sasaki T. Effects of heat stress on temperature regulation in initial exercise. J Human Ergol 1986; 15: 3-12.
16 Torii M, Yamasaki M, Sasaki T, Nakayama T. Fall in skin temperature of exercising man. $\mathrm{Br} J$ Sports Med 1992; 26: 29-32.

17 Mitchell JW, Nadel ER, Stolwijk JAJ. Respiratory weight losses during exercise. J Appl Physiol 1972; 32: 474-6.

18 Ramanathan NL. A new weighting system for mean surface temperature on the human body. J Appl Physiol 1967; 23: $347-52$.

19 Stolwijk JAJ, Hardy JD. Partitional calorimetric studies of responses of man to thermal transients. J Appl Physiol 1966; 21: 967-77.

20 Wojtczak-Jaroszowa J, Banaszkiewicz A. Physical work capacity during the day and night. Ergonomics 1974; 17: 193-8.

21 Hessenmer V, Brück K. Influence of menstrual cycle on thermoregulatory, metabolic, and heart rate responses to exercise at night. J Appl Physiol 1985; 59: 1911-7.

22 Chappuis $P$, Pittet $P$, Jequier E. Heat storage regulation in exercise during thermal transient. J Appl Physiol 1976; 40: 384-92.

23 Nadel ER, Bullard RW, Stolwijk JAJ. Importance of skin temperature in the regulation of sweating. J Appl Physiol 1971; 31: 80-7.

24 Nadel ER, Mitchell JW, Saltin B, Stolwijk JAJ. Peripheral modifications to the central drive of sweating. J Appl Physiol 1971; 31: 828-33

25 Sasaki T, Carlson LD. Effect of a step change in temperature on skin temperature and blood flow. Proc Soc Exper Biol Med 1964; 117: 334-8.

26 Nielsen $M$. Die Regulations der Körpertemperatur bei Muskelarbeit. Scand Arch Physiol 1938; 79: 193-230.

27 Nielsen $M$. Heat production and body temperature during rest and exercise. In: Hardy JD, Gagge AP, Stolwijk JAJ, eds. Physiological and Behavioral Temperature Regulation. Springfield, USA: CC Thomas, 1970; 205-14.

28 Chiba Y. Circadianity and its regulatory mechanisms. In Sasaki T, Chiba Y eds. Chronobiology. Tokyo, Japan: Asakura Shoten, 1978; 11-40 (in Japanese).

29 Arikawa I. Active 80 health plan and sports medicine. 2nd Toyko International Symposium on Sports and Exercise Medicine [TISSEM '89]. 1989; Abstract 32-3.

30 Wilson PK, Fardy PS, Froelicher VF. Cardiac Rehabilitation Adult Fitness and Exercise Testing. Philadelphia, USA: Lea \& Febiger; 1981.

31 Haskell WL. The influence of exercise on the concentrations of triglyceride and cholesterol in human plasma. In: Terjung $\mathrm{RL}$, ed. Exercise and Sport Sciences Reviews Volume 12, New York, USA: Macmillan Publishing, 1984; 205-44.

32 Ehsani LA. Cardiovascular adaptations to exercise training in the elderly. Federation Proc 1987; 46: 1840-3. 